Jurnal Inkofar * Volume 1 No. 1 Juli $2019 *$ ISSN: 2615-3645 (Print) / 2581-2920 (Online)

Tersedia secara online di: http://www.politeknikmeta.ac.id/meta/ojs/

\title{
Implementasi Sistem Pakar Menggunakan Metode Case Based Reasoning dan Nearest Neighbor Untuk Identifikasi Kerusakan Mesin Sepeda Motor Yamaha RX King
}

\author{
Sufajar Butsianto", Arief Nur Hidayat ${ }^{2}$ \\ ${ }^{1}$ Program Studi Teknik Informatika / ${ }^{1}$ Sekolah Tinggi Teknologi Pelita Bangsa / \\ ${ }^{1}$ sufajar@pelitabangsa.ac.id \\ ${ }^{2}$ Program Studi Teknik Informatika / ${ }^{2}$ Sekolah Tinggi Teknologi Pelita Bangsa / \\ ${ }^{2}$ hidayat9530@gmail.com
}

\begin{abstract}
Motorcycle is a transportation vehicle that is widely used by the people of Indonesia in general, Yamaha RX King is one of them. Yamaha RX King has officially stopped being produced since 2009 so that problems with motorcycle engines are faced by many Yamaha RX King motorbike users. The lack of knowledge about Yamaha RX King motorbikes caused losses for Yamaha RX King users both in terms of cost and time. According to those problems, researcher developed web based expert system to identify motorcycle's engine troubles. The aim is to assist users in identifying troubles to the Yamaha $R X$ King motorcycle engine. This Expert system is designed using the waterfall method and implementing the case-based reasoning method and the nearest neighbor algorithm. The expert system is developed using PHP and MySQL used as its database. In addtion this system developed with friendly graphical user interface that makes it easier for users to use the system. Users could find out the type of Yamaha RX King motorcycle engine's problems by selecting the conditions that are available on the system. System knowledge could be changed, added, or deleted by admin. The results of system diagnostic testing with experts have a percentage of suitability of $80 \%$. Hasil pengujian diagnosa sistem dengan pakar memiliki presentase kesesuaian sebesar $80 \%$, this indicates that the expert system works properly according to expert identification.
\end{abstract}

Keywords: expert system, motorcycle Yamaha $R X$ King, metode case-based reasoning, algoritma nearest neighbor

\begin{abstract}
ABSTRAK
Sepeda motor merupakan alat transportasi yang banyak digunakan oleh masyarakat Indonesia pada umumnya, Yamaha RX King adalah salah satunya. Yamaha RX King telah resmi berhenti diproduksi sejak tahun 2009 sehingga kerusakan-kerusakan pada mesin sepeda motor tersebut kini banyak dialami oleh para penggunanya. Kurangnya pengetahuan masyarakat tentang sepeda motor Yamaha RX King mengakibatkan kerugian bagi para pengguna baik dalam hal biaya ataupun waktu. Menyadari hal tersebut, timbul inisiatif untuk membuat sistem pakar identifikasi kerusakan mesin sepeda motor berbasis web. Tujuannya untuk membantu pengguna dalam mengidentifikasi kerusakan mesin sepeda motor Yamaha RX King. Sistem pakar dirancang menggunakan metode waterfall serta dengan mengimplementasikan metode case-based reasoning dan algoritma nearest neighbor. Sistem pakar dibuat dengan pemrograman PHP dan MySQL sebagai basis datanya, dengan tampilan yang user friendly sehingga memudahkan user dalam menggunakan sistem tersebut. Para pengguna dapat mengetahui jenis kerusakan pada mesin sepeda motor Yamaha RX King dengan memilih gejala yang ada pada sistem. Basis pengetahuan sistem dapat diubah, ditambah, ataupun dihapus oleh admin (pakar). Hasil pengujian diagnosa sistem dengan pakar memiliki presentase kesesuaian sebesar $80 \%$, hal ini menunjukkan bahwa sistem pakar berfungsi dengan baik sesuai dengan identifikasi pakar.

Kata Kunci: sistem pakar, sepeda motor Yamaha RX King, metode case-based reasoning, algoritma nearest neighbor

\section{PENDAHULUAN}

Sepeda motor merupakan alat transportasi yang banyak digunakan oleh masyarakat pada umumnya, Yamaha RX King adalah salah satunya. Sepeda motor yang telah resmi berhenti diproduksi pada tahun 2009 ini kini telah menjadi legenda sepeda motor sport yang masih sangat banyak diminati karena akselerasi dan performanya cukup tinggi untuk ukuran sepeda motor berkapasitas $135 \mathrm{cc}$.
\end{abstract}


Meskipun sepeda motor Yamaha RX King ini telah resmi berhenti diproduksi sejak 2009, akan tetapi suku cadang keseluruhan mesin masih diproduksi oleh PT Yamaha Motor, sehingga para pengguna sepeda motor tersebut tidak akan mengalami kesulitan dalam mencari suku cadang kendaraanya. Saat ini pengguna dan penghobi sepeda motor RX king mengalami kesulitan dalam mengidentifikasi kerusakan dan abnormalitas pada kendaraan tersebut, sehingga bagi penulis perlu adanya sebuah tools untuk membantu pengguna dalam mengidentifikasi kerusakan sepeda motor ini tanpa harus ke bengkel terlebih dahulu.

Seiring perkembangan teknologi, kini telah banyak dikembangkan sistem yang mampu mengadopsi cara berfikir manusia yaitu kecerdasan buatan atau artificial intelligence. Sistem pakar merupakan salah satu dari kecerdasan buatan. Oleh karena itu, sistem pakar dapat menjadi salah satu alternatif solusi untuk permasalahan di atas. Sistem pakar (Expert System) adalah merupakan suatu sistem yang menggabungkan antara pengetahuan dengan penelusuran data untuk memecahkan masalah yang secara normal memerlukan keahlian manusia [1]. Dengan mengadopsi kemampuan seorang pakar, dalam hal ini adalah seorang mekanik spesialis sepeda motor Yamaha RX King, maka akan tercipta sebuah sistem yang mampu mengidentifikasi permasalahan pada kendaraan tersebut dengan mudah dan cepat. Pada proses pembuatan sistem pakar identifikasi kerusakan mesin, tentu membutuhkan banyak data kerusakan pada kasus-kasus lama sehingga dapat memprediksi jenis kerusakan pada kasus baru berdasarkan kemiripan-kemiripan gejala yang ada. Pada penelitian ini penulis menggunakan metode case based reasoning, metode case based reasoning menggunakan pendekatan kecerdasan buatan yang menitikberatkan pemecahan masalah dengan didasarkan pada knowledge dari kasus-kasus sebelumnya [2]. Berdasarkan data-data kasus sebelumnya tersebut maka proses identifikasi kerusakan mesin dapat dilakukan melalui perhitungan kemiripan gejala pada kasus baru dengan kasus lama menggunakan algoritma nearest neighbor. Nearest neighbor adalah pendekatan untuk mencari kasus dengan menghitung kedekatan antara kasus baru dengan kasus lama berdasarkan pencocokan bobot [3].

Tujuan dari penelitian ini adalah mengimplementasikan metode case based reasoning dan nearest neighbor dalam pembuatan sistem pakar untuk identifikasi kerusakan mesin sepeda motor Yamaha RX King, dengan penelitian ini diharapkan dapat membantu para pengguna dan penghobi sepeda motor tua tersebut dalam mengidentifikasi kerusakan serta cara perbaikannya. Aplikasi yang dibuat nantinya juga diharapkan dapat mengatasi keterbatasan tenaga ahli atau pakar mesin sepeda motor Yamaha RX King. Tetapi tidak menggantikannya secara penuh, hanya diharapkan mendekati kemampuan dan kecerdasan pakar dalam mengidentifikasi kerusakan dan perbaikan sepeda motor Yamaha RX King.

\section{TINJAUAN PUSTAKA}

\subsection{Sistem Pakar}

Sistem pakar (expert system) secara umum adalah sistem yang berusaha mengadopsi pengetahuan manusia ke dalam komputer, agar komputer dapat menyelesaikan masalah seperti yang biasa dapat dilakukan oleh para ahli. Atau dengan kata lain sistem pakar adalah sistem yang didesain dan diimplementasikan dengan bantuan bahasa pemrograman tertentu untuk dapat menyelesaikan masalah seperti yang dilakukan oleh para ahli. Dengan sistem ini diharapkan orang awam dapat menyelesaikan masalah tertentu baik sedikit rumit atau rumit sekalipun tanpa bantuan para ahli dalam bidang tersebut. Sedangkan bagi para ahli, sistem ini dapat digunakan sebagai asisten yang berpengalaman [4]. Perbandingan sistem konvensional dengan sistem pakar sebagai berikut [4]:

1. Sistem Konvensional

a. Informasi dan pemrosesan umumnya digabung dalam satu program Sequential.

b. Program tidak pernah salah (kecuali pemrogramnya yang salah).

c. Tidak menjelaskan mengapa input dibutuhkan atau bagaimana hasil diperoleh.

d. Data harus lengkap.

e. Perubahan pada program merepotkan.

2. Sistem Pakar
a. Knowledge base terpisah dari mekanisme pemrosesan.
b. Program bisa melakukan kesalahan.
c. Penjelasan merupakan bagian dari sistem pakar.
d. Data tidak harus lengkap.
e. Perubahan pada rules dapat dilakukan dengan mudah. 


\subsection{Case Based Reasoning}

Metode case based reasoning menggunakan pendekatan kecerdasan buatan yang menitikberatkan pemecahan masalah dengan didasarkan pada knowledge dari kasus-kasus sebelumnya [5]. Secara umum, metode ini terdiri dari 4 langkah yaitu :

\subsubsection{Retrieve}

Pada saat terjadi permasalahan baru, pertama-tama sistem akan melakukan proses retrieve. Yaitu pengenalan masalah dan pencarian persamaan masalah pada database.

\subsubsection{Reuse}

Proses ini sistem akan menggunakan informasi permasalahan sebelumnya yang memiliki kesamaan untuk menyelesaikan permasalahan yang baru dan menggunakan kembali informasi dan pengetahuan dalam kasus tersebut untuk mrngatasi masalah. Pada proses reuse akan menyalin, menyeleksi, dan melengkapi informasi yang akan digunakan.

\subsubsection{Revise}

Proses revise adalah meninjau dan memperbaiki kembali usulan solusi.

\subsubsection{Retain}

Proses ini akan mengindeks, mengintegrasi, dan mengekstrak solusi yang baru. Selanjutnya solusi yang baru tersebut akan ditambahkan kedalam basis pengetahuan untuk menyelesaikan permasalahan yang akan datang. Tentunya, permasalahan yang akan diselesaikan adalah permasalahan yang memiliki kesamaan dengannya.

\subsection{Nearest Neighbor}

Nearest Neighbor adalah pendekatan untuk mencari kasus dengan menghitung nilai kedekatan antara kasus baru dengan kasus lama, yaitu berdasarkan pada pencocokan bobot dari sejumlah fitur yang ada [3]. Adapun rumus untuk melakukan perhitungan antara dua kasus adalah sebagai berikut :

Keterangan :

$$
\operatorname{similarity}(T, S)=\frac{\sum_{i=1}^{n} f\left(T_{i}, S_{i}\right) x w_{i}}{w_{i}}
$$

T: kasus baru (target)

S: kasus yang ada dalam penyimpanan (source)

n: jumlah atribut

i: jumlah atribut dalam masing-masing kasus

f: fungsi similarity atribut $\mathrm{i}$ antara kasus $\mathrm{T}$ dan kasus $\mathrm{S}$

Wi: bobot yang diberikan pada atribut ke $\mathrm{i}$

Kedekatan biasanya berada pada nilai antara $0 \mathrm{~s} / \mathrm{d} 1$. Nilai 0 artinya kedua kasus mutlak tidak mirip, sebaliknya untuk nilai 1 kasus mirip dengan mutlak.

\section{METODOLOGI PENELITIAN}

\subsection{Objek Penelitian}

Objek penelitian adalah permasalahaan yang diteliti. Dalam skripsi ini, yang menjadi objek penelitian adalah sepeda motor Yamaha RX King tentang macam-macam kerusakan pada jenis sepeda motor tersebut dan bagaimana cara penanggulangannya. Penelitian akan dilakukan di sebuah bengkel yang bernama Bengkel Tyan BTRAC. Bertempat di Jl. Darma Kusuma Kp Pasir Limus RT 07 RW 04 Desa Wangun Harja, Kec. Cikarang Utara, Kab. Bekasi. Bengkel Tyan BTRAC merupakan sebuah bengkel khusus sepeda motor Yamaha RX King, bengkel yang berawal dari hobi si pemilik bengkel itu sendiri yaitu bapak Listyan yang merupakan anggota dari salah satu komunitas pecinta sepeda motor Yamaha RX King BTRAC (Bantul RX King Automotive Club). Bengkel ini hanya menerima perbaikan dan modifikasi khususnya sepeda motor Yamaha RX King, oleh sebab itu penulis memutuskan untuk melakukan penelitian di Bengkel tersebut. 


\subsection{Tahap Penelitian}

Penelitian ini dilakukan dengan mengikuti tahapan-tahapan sesuai kerangka berfikir yang meliputi metode pengumpulan data dan metode pengembangan sistem. Berikut adalah alur rencana penelitian :

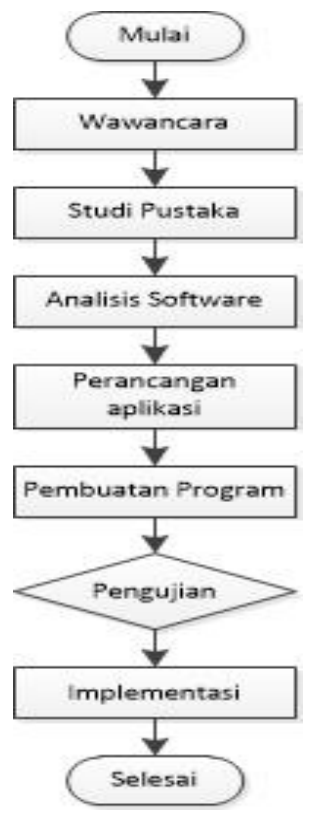

Gambar 1. Rencana Penelitian

\subsection{Metodologi Pengumpulan Data}

Metodologi pengumpulan data yang digunakan meliputi tiga metode pengumpulan data, yaitu :

1. Metode Studi Pustaka

Dilakukan dengan cara mempelajari beberapa penelitian yang sejenis, buku, jurnal, serta artikel yang mendukung dengan topik yang akan dibahas dalam penyusunan laporan skripsi ini. Dari hasil tersebut didapatkan bagaimana membangun suatu sistem pakar yang antara lain meliputi komponen-komponen sistem pakar dan pemodelan dalam membangun sistem pakar. Selain itu data diperoleh dari situs-situs internet yang berhubungan dengan penyusunan laporan skripsi ini. Data-data yang diperoleh dari buku dan internet diperlukan untuk dipelajari mengenai masalah yang akan dibahas dalam skripsi ini. Adapun data-data dan buku-buku atau artikel artikel-artikel yang digunakan dalam penulisan skripsi ini terdapat dalam daftar pustaka.

2. Metode Observasi

Pada metode pengamata (observasi) ini dilakukan peninjauan dan penelitian langsung di lapangan untuk memperoleh dan mengumpulkan data yang dibutuhkan. Pengamatan dilakukan di bengkel Tyan BTRAC yang bergerak dalam bidang jasa servis dan modifikasi sepeda motor khususnya jenis sepeda motor Yamaha RX King. Selain itu bengkel tersebut juga melakukan penjualan berbagai macam komponen dan aksesoris sepeda motor Yamaha RX King. Pengamatan ini dilakukan pada tanggal 1 Juli 2018 - 30 September 2018 bertempat di Jl. Darma Kusuma Kp Pasir Limus RT 07 RW 04 Desa Wangun Harja, Kec. Cikarang Utara, Kab. Bekasi.

3. Metode Wawancara

Wawancara dilakukan denga cara mewawancarai secara langsung pihak-pihak terkait, yang berguna untuk mendapatkan informasi maupun data-data yang dibutuhkan untuk perancangan dan pembangunan sistem yang akan dibuat, antara lain :

a. Wawancara terhadap pihak bengkel, dalam ini seorang pakar, guna mendapatkan gambaran mengenai sistem yang akan dibuat.

b. Wawancara terhadap pelanggan bengkel, dalam hal ini mewakili sebagai pihak user guna mendapatkan informasi maupun data kebutuhan seorang user terkait sistem yang akan dibuat. 


\section{HASIL DAN PEMBAHASAN}

4.1. Analisa Metode Case Based Reasoning Dan Nearest Neighbor

Analisa metode case based reasoning dan nearest neighbor pada sistem pakar identifikasi kerusakan mesin sepeda motor yamaha RX King ini dilakukan dengan beberapa langkah. Berikut flowchart sistem pakar menggunakan metode CBR :

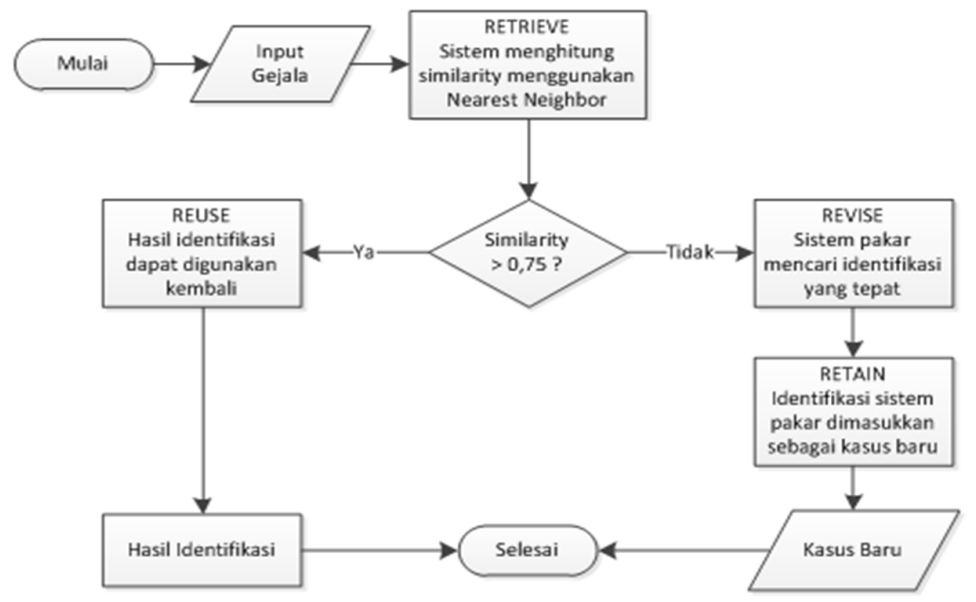

Gambar 2. Flowchart Sistem Pakar

\subsection{Analisa Basis Pengetahuan}

Analisa basis pengetahuan merupakan inti dari sistem pakar identifikasi kerusakan mesin sepeda motor Yamaha RX King yang akan mempresentasikan pengetahuan dari seorang pakar mesin sepeda motor Yamaha RX King. Analisa basis pengetahuan dibangun untuk mengetahui jenis kerusakan yang teridentifikasi dari 11 kerusakan yang termasuk ke dalam kategori kerusakan mesin sepeda motor Yamaha RX King. Setiap gejala (memiliki nilai bobot parameter) yang dialami oleh pengguna sepeda motor tersebut akan dicocokkan dengan basis pengetahuan yang akan dibangun sehingga menghasilkan hasil identifikasi kerusakan mesin yang dialami oleh pengguna sepeda motor tersebut. Berikut jenis kerusakan dan tabel gejala pada basis pengetahuan sistem :

Jenis kerusakan :
A : Kerusakan pada kick starter
B : Kerusakan pada sistem pembakaran
$\mathrm{C}:$ Kerusakan pada mesin atas
D : Kerusakan pada spul
E : Kerusakan pada aki
F : Kerusakan pada mesin kanan
$\mathrm{G}$ : Kerusakan pada mesin kiri
$\mathrm{H}$ : Kerusakan pada mesin tengah
I : Kerusakan pada karburator
$\mathrm{J}:$ Kerusakan pada transmisi
$\mathrm{K}$ : Kerusakan pada pompa oli samping 
Tabel 1. Daftar Gejala

\begin{tabular}{|c|c|c|c|c|c|c|c|c|c|c|c|c|c|}
\hline \multirow{2}{*}{ Kode } & \multirow{2}{*}{ Gejala Kerusakan } & \multicolumn{11}{|c|}{ Jenis Kerusakan } & \multirow{2}{*}{ Bobot } \\
\hline & & $\mathrm{A}$ & $\mathrm{B}$ & $\mathrm{C}$ & $\mathrm{D}$ & $E$ & $\mathrm{~F}$ & $\mathrm{G}$ & $\mathrm{H}$ & $\mathrm{I}$ & $\mathrm{J}$ & $\mathrm{K}$ & \\
\hline G1 & Kick starter ngelos & $\mathrm{x}$ & & & & & & & & & & & 3 \\
\hline G2 & Kick starter tidak kembali ke posisi semula & $\mathrm{x}$ & & & & & & & & & & & 1 \\
\hline G3 & Terdapat bunyi keras ketika engkol kick starter & $\mathrm{x}$ & & & & & & & & & & & 5 \\
\hline G4 & Percikan bunga api pada busi kecil & & $\mathrm{x}$ & & & & & & & & & & 5 \\
\hline G5 & Coil rusak & & $\mathrm{x}$ & & & & & & & & & & 3 \\
\hline G6 & CDI rusak & & $\mathrm{x}$ & & & & & & & & & & 3 \\
\hline G7 & Kumparan spul meleleh/terbakar & & $\mathrm{x}$ & & & & & & & & & & 5 \\
\hline G8 & Mesin bagian atas berisik & & & $\mathrm{x}$ & & & & & & & & & 1 \\
\hline G9 & Piston aus & & & $\mathrm{x}$ & & & & & & & & & 3 \\
\hline G10 & Ring piston aus & & & $\mathrm{x}$ & & & & & & & & & 1 \\
\hline G11 & Liner blok mesin (rumah piston) aus & & & $\mathrm{x}$ & & & & & & & & & 1 \\
\hline G12 & Ukuran squish head tidak sesuai kapasitas & & & $\mathrm{x}$ & & & & & & & & & 3 \\
\hline G13 & Lampu redup dan aki cepat tekor & & & & $\mathrm{x}$ & & & & & & & & 5 \\
\hline G14 & Kumparan spul pengisian terbakar & & & & $\mathrm{x}$ & & & & & & & & 3 \\
\hline G15 & Arus dari kiprok lemah & & & & $\mathrm{x}$ & & & & & & & & 1 \\
\hline G16 & Klakson tidak berbunyi/bunyi pelan & & & & & $\mathrm{x}$ & & & & & & & 5 \\
\hline G17 & Lampu sein redup/tidak menyala & & & & & $\mathrm{x}$ & & & & & & & 3 \\
\hline G18 & Lampu indikator spedo redup & & & & & $\mathrm{x}$ & & & & & & & 1 \\
\hline G19 & Suara brisik di bak mesin kanan & & & & & & $\mathrm{x}$ & & & & & & 5 \\
\hline G20 & Kampas kopling aus & & & & & & $\mathrm{x}$ & & & & & & 3 \\
\hline G21 & Plat kopling aus & & & & & & $\mathrm{x}$ & & & & & & 3 \\
\hline G22 & Suara brisik di bak mesin kiri & & & & & & & $\mathrm{x}$ & & & & & 1 \\
\hline G23 & Kopling kurang maksimal (ngelos) & & & & & & & $\mathrm{x}$ & & & & & 5 \\
\hline G24 & Oli mesin bocor masuk ke bak mesin kiri & & & & & & & $\mathrm{x}$ & & & & & 3 \\
\hline G25 & Seal kruk as bocor & & & & & & & $\mathrm{x}$ & & & & & 3 \\
\hline G26 & Spi magnet pecah & & & & & & & $\mathrm{x}$ & & & & & 1 \\
\hline G27 & Baut penahan magnet kendor & & & & & & & $\mathrm{x}$ & & & & & 5 \\
\hline G28 & Rumah kopling (gigi primer) aus & & & & & & $\mathrm{x}$ & & & & & & 3 \\
\hline G29 & Suara berisik di bak mesin tengah & & & & & & & & $\mathrm{x}$ & & & & 1 \\
\hline G30 & Kruk as tidak balance & & & & & & & & $\mathrm{x}$ & & & & 3 \\
\hline G31 & Batang piston (stang seher) bengkok & & & & & & & & $\mathrm{x}$ & & & & 5 \\
\hline G32 & Bearing kruk as pecah & & & & & & & & $\mathrm{x}$ & & & & 3 \\
\hline G33 & Seal karburator bocor & & & & & & & & & $\mathrm{x}$ & & & 3 \\
\hline G34 & Tenaga mesin kurang & & & & & & & & & $\mathrm{x}$ & & & 1 \\
\hline G35 & Ketika mesin dihidupkan tidak langsam & & & & & & & & & $\mathrm{x}$ & & & 1 \\
\hline G36 & Filter udara kotor & & & & & & & & & $\mathrm{x}$ & & & 3 \\
\hline G37 & Ketika turun gas knalpot nembak & & & & & & & & & $\mathrm{x}$ & & & 5 \\
\hline G38 & Tuas transmisi keras & & & & & & & & & & $\mathrm{x}$ & & 1 \\
\hline G39 & Tuas transmisi tidak dapat dipindah gigi & & & & & & & & & & $\mathrm{x}$ & & 5 \\
\hline G40 & Suara keras ketika perpindahan gigi & & & & & & & & & & $\mathrm{x}$ & & 1 \\
\hline G41 & Mesin cepat panas & & & & & & & & & & & $\mathrm{x}$ & 3 \\
\hline G42 & Busi berwarna hitam kering & & & & & & & & & & & $\mathrm{x}$ & 5 \\
\hline G43 & Busi mati (berwarna hitam basah) & & & & & & & & & & & $\mathrm{x}$ & 3 \\
\hline G44 & Oli samping menetes di bak mesin kanan & & & & & & & & & & & $\mathrm{x}$ & 1 \\
\hline G45 & Oli samping tidak tersuplai lancar & & & & & & & & & & & $\mathrm{x}$ & 5 \\
\hline
\end{tabular}

\subsection{Perhitungan Nearest Neighbor Dengan Bobot Dari Pakar}

Perhitungan nilai similarity kasus baru dengan kasus lama pada basis pengetahuan adalah sebagai berikut :

Contoh gejala kasus baru :

- $\quad$ Mesin cepat panas

- $\quad$ Tenaga mesin kurang

- $\quad$ Suara berisik di bak mesin kiri

- $\quad$ Kopling kurang maksimal (ngelos)

- $\quad$ Oli mesin bocor masuk ke bak mesin kiri

- Baut penahan magnet kendor

- $\quad$ Arus dari kiprok lemah

- $\quad$ Percikan bunga api pada busi kecil

- $\quad$ Mesin bagian atas berisik 


\begin{tabular}{|l|}
\hline Kasus Baru \\
\hline Gejala : \\
Kick starter ngelos \\
Kick starter tidak kembali ke posisi semula \\
Suara berisik di bak mesin kiri \\
Kopling kurang maksimal (ngelos) \\
Oli mesin bocor masuk ke bak mesin kiri \\
Baut penahan magnet kendor \\
Arus dari kiprok lemah \\
Percikan bunga api kecil \\
Mesin bagian atas berisik \\
\hline Jenis Kerusakan : ??? \\
\hline
\end{tabular}

\begin{tabular}{|l|l|} 
Kasus 7 \\
\hline Gejala : \\
Suara berisik di bak mesin kiri \\
Koling kurang maksimal (ngelos) \\
Seal kruk as bocor \\
Spi magnet pecah \\
Baut penahan magnet kendor \\
Jenis Kerusakan : Kerusakan mesin kiri \\
\hline
\end{tabular}

\section{Gambar 3. Proses Retrieve Contoh Kasus Baru Dengan Kasus 7}

Perhitungan similarity kasus baru dengan kasus 7

- $\quad$ Bobot gejala kerusakan kasus 7

Suara berisik di bak mesin kiri $\quad: 1$

Kopling kurang maksimal (ngelos) : : 5

Oli mesin bocor masuk ke bak mesin kiri : 3

Seal kruk as bocor $\quad: 3$

Spi magnet pecah $\quad: 1$

Baut penahan magnet kendor $\quad: 5$

- $\quad$ Bobot gejala yang sama dengan kasus baru

Suara berisik di bak mesin kiri $\quad: 1$

Kopling kurang maksimal (ngelos) $\quad: 5$

Oli mesin bocor masuk ke bak mesin kiri : 3

Baut penahan magnet kendor $\quad: 5$

$$
\begin{aligned}
\text { Similarity } & =[(1 * 1)+(1 * 5)+(1 * 3)+(0 * 3)+(0 * 1)+(1 * 5)] \\
& =0,7777
\end{aligned}
$$

Berikut hasil perhitungan similarity kasus baru dengan 11 kasus lama pada basis pengetahuan :

Tabel 2. Hasil Perhitungan Similarity

\begin{tabular}{|c|c|}
\hline Kasus & Hasil Similarity \\
\hline KB \& K1 & 0,4444 \\
\hline KB \& K2 & 0,3125 \\
\hline KB \& K3 & 0,1111 \\
\hline KB \& K4 & 0 \\
\hline KB \& K5 & 0 \\
\hline KB \& K6 & 0 \\
\hline KB \& K7 & 0,7777 \\
\hline KB \& K8 & 0 \\
\hline KB \& K9 & 0 \\
\hline KB \& K10 & 0 \\
\hline KB \& K11 & 0 \\
\hline
\end{tabular}


Solusi yang akan diberikan sistem pada kasus baru berdasarkan pada nilai similarity tertinggi antara kasus baru dengan kasus lama (reuse).

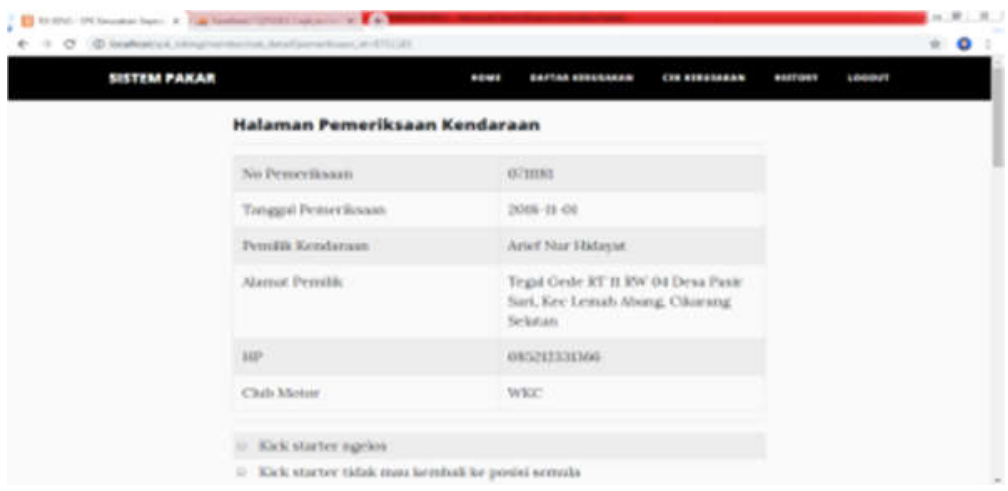

Gambar 4. Implementasi Interface Pemilihan Gejala

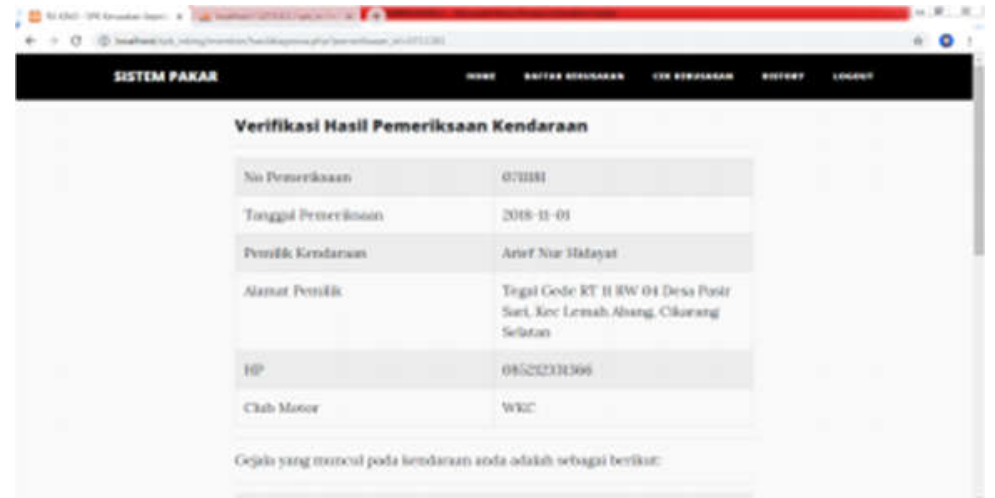

Gambar 5. Implementasi Interface Hasil Pemeriksaan

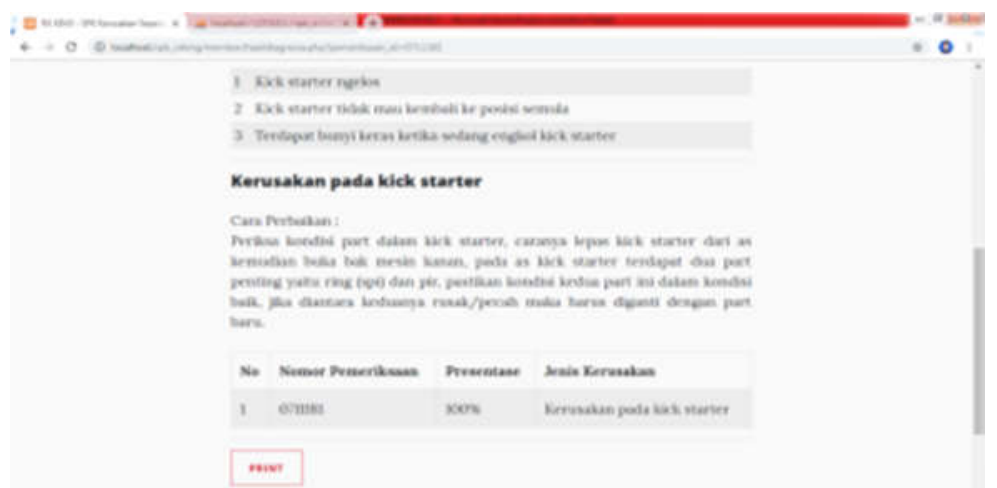

Gambar 6. Implementasi Interface Hasil Pemeriksaan (Lanjutan)

\subsection{Pengujian Perbandingan Diagnosa Sistem Dengan Diagnosa Pakar}

Pengujian ini dilakukan dengan membandingkan hasil diagnosa sistem dengan diagnosa pakar. Pengujian ini bertujuan untuk mengetahui kesesuaian diagnosa yang diberikan sistem dengan diagnosa pakar. Pada pengujian ini Bapak Listyan selaku pemilik sekaligus mekanik dari bengkel Tyan BTRAC memberikan diagnosa terhadap 10 data percobaan yang berisi gejala-gejala yang dipilih berdasarkan kasus sesuai dengan basis pengetahuan sistem pakar. Hasil diagnosa dari Bapak Listyan selaku pakar mesin sepeda motor Yamaha RX King tersebut selanjutnya dibandingkan dengan hasil diagnosa sistem. Hasil pengujian perbandingan diagnosa sistem dengan diagnosa pakar dapat dilihat pada tabel berikut : 
Tabel 3. Perbandingan Diagnosa Sistem Dengan Diagnosa Pakar

\begin{tabular}{|c|c|c|c|c|}
\hline $\begin{array}{c}\text { Nomor } \\
\text { Percobaa } \\
\mathrm{n}\end{array}$ & Gejala yang dimasukkan & Diagnosa Sistem & Diagnosa Pakar & $\begin{array}{c}\text { Keteran } \\
\text { gan }\end{array}$ \\
\hline 1 & $\begin{array}{l}\text { 1. Kick starter ngelos } \\
\text { 2. Kick starter tidak mau } \\
\text { kembali } \\
\text { keposisi semula } \\
\text { 3. Terdapat bunyi keras ketika } \\
\text { sedang engkol kick starter } \\
\text { 4. Suara berisik di bak mesin } \\
\text { kanan }\end{array}$ & $\begin{array}{l}\text { Kerusakan pada } \\
\text { kick starter } \\
(100 \%) \\
\text { Kerusakan } \\
\text { mesin kanan } \\
(25 \%)\end{array}$ & $\begin{array}{l}\text { Kerusakan pada } \\
\text { kick stsrter }\end{array}$ & Sesuai \\
\hline 2 & $\begin{array}{l}\text { 1. Suara berisik pada bak mesin } \\
\text { tengah } \\
\text { 2. Kruk as tidak balance } \\
\text { 3. Batang piston (stang seher) } \\
\text { bengkok } \\
\text { 4. Bearing kruk as pecah }\end{array}$ & $\begin{array}{l}\text { Kerusakan } \\
\text { mesin tengah } \\
\quad(100 \%)\end{array}$ & $\begin{array}{c}\text { Kerusakan mesin } \\
\text { tengah }\end{array}$ & Sesuai \\
\hline 3 & $\begin{array}{l}\text { 1. Mesin bagian atas berisik } \\
\text { 2. percikan bunga api pada busi } \\
\text { kecil } \\
\text { 3. Coil Rusak } \\
\text { 4. CDI rusak } \\
\text { 5. Kumparan sepull meleleh atau } \\
\text { terbakar }\end{array}$ & $\begin{array}{l}\text { Kerusakan } \\
\text { system } \\
\text { pembakaran } \\
\quad(100 \%) \\
\text { Kerusakan } \\
\text { mesin atas } \\
(20 \%)\end{array}$ & $\begin{array}{c}\text { Kerusakan system } \\
\text { pembakaran }\end{array}$ & Sesuai \\
\hline 4 & $\begin{array}{l}\text { 1. Suara berisik di bak mesin } \\
\text { kiri } \\
\text { 2. Tuas transmisi keras } \\
\text { 3. Tuas transmisi tidak dapat } \\
\text { dipindah gigi } \\
\text { 4. Suara keras ketika } \\
\text { perpindahan gigi }\end{array}$ & $\begin{array}{l}\text { Kerusakan } \\
\text { transmisi } \\
(100 \%) \\
\text { Kerusakan } \\
\text { mesin kiri } \\
(17 \%) \\
\end{array}$ & $\begin{array}{c}\text { Kerusakan } \\
\text { transmisi }\end{array}$ & Sesuai \\
\hline 5 & $\begin{array}{l}\text { 1. Mesin cepat panas } \\
\text { 2. Busi berwarna hitam kering } \\
\text { 3. Busi mati (berwarna hitam } \\
\text { basah) } \\
\text { 4. Oli samping menetes di bak } \\
\text { mesin kanan } \\
\text { 5. Oli samping tidak tersuplai } \\
\text { lancar }\end{array}$ & $\begin{array}{c}\text { Kerusakan } \\
\text { pompa oli } \\
\text { samping }(100 \%)\end{array}$ & $\begin{array}{l}\text { Kerusakan pompa } \\
\text { oli samping }\end{array}$ & sesuai \\
\hline
\end{tabular}

Tabel 4. Perbandingan Diagnosa Sistem Dengan Diagnosa Pakar (Lanjutan)

\begin{tabular}{|c|l|c|c|c|}
\hline $\begin{array}{c}\text { Nomor } \\
\text { Percobaa } \\
\mathrm{n}\end{array}$ & \multicolumn{1}{|c|}{ Gejala yang dimasukkan } & Diagnosa Sistem & Diagnosa Pakar & $\begin{array}{c}\text { Keteran } \\
\text { gan }\end{array}$ \\
\hline 6 & $\begin{array}{l}\text { 1. Klakson tidak } \\
\text { berbunyi/berbunyi pelan } \\
\text { 2. Lampu sein redup/tidak } \\
\text { menyala } \\
\text { 3. Lampu indicator spedo redup }\end{array}$ & $\begin{array}{c}\text { Kerusakan aki } \\
(100 \%)\end{array}$ & Kerusakan aki & Sesuai \\
\hline
\end{tabular}


Jurnal Inkofar * Volume 1 No. 1 Juli 2019 * ISSN: 2615-3645 (Print) / 2581-2920 (Online)

Tersedia secara online di: http://www.politeknikmeta.ac.id/meta/ojs/

\begin{tabular}{|c|c|c|c|c|}
\hline 7 & $\begin{array}{l}\text { 1. Lampu sein redup/tidak } \\
\text { menyala } \\
\text { 2. Lampu indicator spedo redup } \\
\text { 3. Kopling kurang } \\
\text { maksimal(ngelos) } \\
\text { 4. Oli mesin bocor masuk ke } \\
\text { bak mesin kiri } \\
\text { 5. Seal kruk as bocor }\end{array}$ & $\begin{array}{l}\text { Kerusakan aki } \\
\qquad(67 \%) \\
\text { Kerusakan } \\
\text { mesin kiri } \\
(50 \%)\end{array}$ & $\begin{array}{l}\text { Kerusakan mesin } \\
\text { kiri }\end{array}$ & $\begin{array}{l}\text { Tidak } \\
\text { sesuai }\end{array}$ \\
\hline 8 & $\begin{array}{l}\text { 1. Piston aus } \\
\text { 2. Ring piston Aus } \\
\text { 3. Liner blok mesin (rumah } \\
\text { piston) Aus } \\
\text { 4. Ukuran squish head tidak } \\
\text { sesuai kapasitas }\end{array}$ & $\begin{array}{l}\text { Kerusakan } \\
\text { mesin atas } \\
(80 \%)\end{array}$ & $\begin{array}{c}\text { Kerusakan mesin } \\
\text { atas }\end{array}$ & Sesuai \\
\hline 9 & $\begin{array}{l}\text { 1. Percikan bunga api pada busi } \\
\text { kecil } \\
\text { 2. Coil rusak } \\
\text { 3. CDI rusak } \\
\text { 4. Kumparan spull meleleh atau } \\
\text { terbakar }\end{array}$ & $\begin{array}{c}\text { Kerusakan } \\
\text { system } \\
\text { pembakaran } \\
(100 \%)\end{array}$ & $\begin{array}{c}\text { Kerusakan system } \\
\text { pembakaran }\end{array}$ & Sesuai \\
\hline 10 & $\begin{array}{l}\text { 1. Tuas transmisi keras } \\
\text { 2. Tuas transmisi tidak dapat } \\
\text { dipindah gigi } \\
\text { 3. Busi berwarna hitam kering } \\
\text { 4. Busi mati berwarna hitam } \\
\text { basah } \\
\text { 5. Oli samping tidak tersuplai } \\
\text { lancar }\end{array}$ & $\begin{array}{c}\text { Kerusakan } \\
\text { pompa oli } \\
\text { samping }(60 \%) \\
\\
\text { Kerusakan } \\
\text { transmisi }(60 \%)\end{array}$ & $\begin{array}{l}\text { Kerusakan pompa } \\
\text { oli samping }\end{array}$ & $\begin{array}{l}\text { Tidak } \\
\text { sesuai }\end{array}$ \\
\hline
\end{tabular}

Presentase kesesuaian : (Hasil yang sesuai / Jumlah percobaan) x 100\%

$$
\begin{aligned}
& :(8 / 10) \times 100 \% \\
& : 80 \%
\end{aligned}
$$

Dari hasil pengujian perbandingan diagnosa sistem dengan diagnosa pakar di atas, dapat disimpulkan bahwa sistem dapat memberikan diagnosa $80 \%$ sama dengan diagnosa yang diberikan oleh pakar. Hal ini menunjukan bahwa sistem berfungsi dengan baik dalam melakukan proses identifikasi kerusakan mesin sepeda motor Yamaha RX King.

\section{KESIMPULAN DAN SARAN}

\subsection{Kesimpulan}

Berdasarkan hasil penelitian yang telah dilakukan dan pembahasan pada bab-bab sebelumnya, maka dapat ditarik kesimpulan sebagai berikut :

1. Sistem yang dirancang dapat mengadopsi pengetahuan seorang pakar ke dalam suatu sistem komputer, dengan menggunakan metode perancangan sistem yang dilakukan berurutan atau secara linear yakni metode waterfall,serta menggunakan metode case based reasoning dengan algoritma nearest neighbor dalam penelurusan masalah untuk mendeteksi kerusakan mesin sepeda motor Yamaha RX King.

2. Hasil pengujian perbandingan diagnosa sistem dengan diagnosa pakar menunjukkan sistem memiliki presentase kesesuaian sebesar $80 \%$ dalam mengidentifikasi kerusakan mesin sepeda motor Yamaha RX King. Hal ini menunjukkan bahwa sistem pakar berfungsi dengan baik sesuai dengan identifikasi pakar. 


\subsection{Saran}

Adapun saran-saran dari penulis untuk perancangan program sistem pakar identifikasi kerusakan mesin sepeda motor Yamaha RX King ini adalah adalah sebagai berikut :

1. Sistem pakar ini hendaknya dilakukan evaluasi secara berkala sehingga dapat dihasilkan sistem yang lebih baik.

2. Sistem pakar ini dapat dikembangkan lagi menggunakan data-data gejala kerusakan dan jenis kerusakan yang lebih banyak agar hasil identifikasi lebih akurat.

3. Proses pembobotan yang digunakan pada penelitian ini adalah pembobotan oleh satu pakar dan bersifat obyektif, sehingga untuk penelitian selanjutnya disarankan untuk pembobotannya dilakukan beberapa pakar dan diambil rata-rata agar diperoleh pembobotan yang lebih baik.

\section{DAFTAR PUSTAKA}

[1] Andriana. 2008. Sistem Penalaran Komputer Berbasis Kasus (Case Based Reasoning). Yogyakarta: Ardana Media, p.17

[2] Arhami, Muhammad. 2005. Konsep Dasar Sistem Pakar. Yogyakarta: Andi.

[3] Kusrini, Emha T.L. 2009. Algoritma Data Mining. Yogyakarta : Andi Offset . p. 93

[4] Kusumadewi, S. 2003. Arttificial Inteligence Tehnik dan Aplikasinya. Yogyakarta: Graha Ilmu.

[5] Minarni, dan Warman, I. 2017. Sistem Pakar Identifikasi Penyakit Tanaman Padi Menggunakan Case Based Reasoning. Jurnal Seminar Nasional Aplikasi Tenologi Informasi (SNATi) ISSN: 1907-5022 